\title{
Reproduction of human potential of JSC "Russian Railways" - a source of increasing labor productivity
}

\author{
Anatoliy Davydov ${ }^{1, *}$, Alexey Dementev ${ }^{1}$, and Vladimir Burovtsev ${ }^{1}$ \\ ${ }^{1}$ Siberian Transport University, Dusi Kovalchuk st., 191, 630049, Novosibirsk, Russia
}

\begin{abstract}
The ongoing reform of Russian railway transport entailed a change in the form of ownership and status previously all known monopoly represented by the Ministry of Railways of Russia, and its transformation into the Open Joint Stock Company "Russian Railways". The change in the form of ownership of one of the largest subjects of the transport services market in Russia had a certain effect on the competitiveness of the country's transport system and, in some way, reduced the level of monopolization of railway transportation. The methods for calculating the labor productivity of transport companies in Russia generally require a deeper method of measuring the performance of personnel, based on assessing the level of development of the company's human potential in modern economic conditions, when the relationship between the results of personnel work and the company's targets determines its competitiveness. The authors propose a new methodology for managing labor productivity and employee incentives, which is caused by the actualization of a number of functions of personnel management of transport companies and the transformation of production activities depending on changes in the external environment, which previously did not play a fundamental role, but now have a decisive influence on the efficiency of the company's activity and social production of the country. Assessment of the performance of companies can also cause problems with the management system of labor productivity and human development, if the strategic goals and objectives of the company's development are not known to a particular employee, are not balanced or outside of its sphere of influence.
\end{abstract}

\section{Introduction}

In the historical evolution of the development of methods for assessing the efficiency and effectiveness of labor, most of the personnel remuneration systems used in Russian transport companies were based on the amount of wages, the rate of its growth, without paying close attention to the growth rates of labor productivity. As a result, in the last three years (2014 - 2017) of work of the company "Russian Railways", with a growth rate of labor productivity from $5.9 \%$ to $7.7 \%$ per year, the increase in wages for collective labor

\footnotetext{
*Corresponding author: burovtsevvv@mail.ru
} 
results averaged no more than $4.0 \%$.

Such an increase in the wage rate didn't reflect the growth rate of the company's labor productivity (Fig. 1), but only kept the level of wages of the company's personnel at the inflation level.

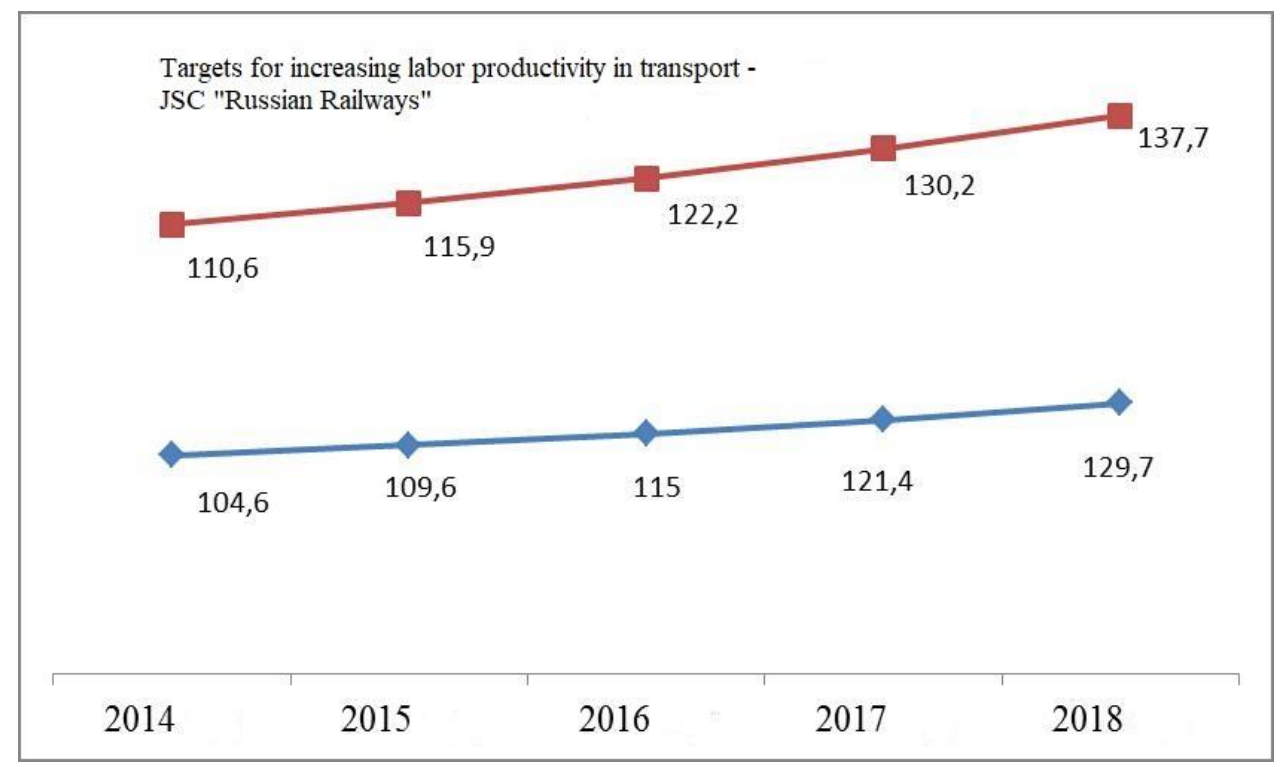

Fig. 1. Targets for increasing labor productivity by 2013 (Government Resolution of the Russian Federation of 09.07.2014).

Many managers of large transport companies use the indicator "labor productivity" as the main indicator of efficiency assessment in order to justify the minimum wage increase that they already assigned to their employees. In general, few of the employees or managers of the middle and linear levels of administration, and most specialists were satisfied with such a system of remuneration $[2,5]$.

When developing a new methodology for managing labor productivity based on the development of the company's human potential, the scientific approach is to clearly substantiate the volume of freight and passenger transportation, the elemental cost structure in accordance with long-term, medium-term and short-term development goals of the company. The essence of the proposed methodology for managing labor productivity on the basis of increasing human efficiency is a kind of new thinking for managers, aimed at the continuous improvement of the company's economic position, based on the adaptation of the company's current management system to the changing conditions of the external and industrial environment $[2,3]$.

\section{Labor productivity}

This is the one of the key indicators of the assessment of not only the company's production activities as a whole, but primarily the assessment of the efficiency of the company's management. The growth rate of labor productivity in the company should not be lower than the growth rate of this indicator in the Russian Federation (Fig. 1).

Figure 2 shows the growth rates of productivity of large railway companies in the world (Fig. 2). If we assess the data of the basic conditionally-natural indicator available in open sources for calculating the productivity of work of the railway transport - given tonnekilometres, then JSC "Russian Railways" ranks third in terms of productivity after the 1st 
class railway companies of the USA and Canada, being ahead of the Europe, China, Japan [1].

It should be noted that the main work measuring instrument for railway transport is an equated turnover of goods. Another indicator for calculating labor productivity is not offered by transport science. However, various methods of calculating it in modern conditions do not allow a direct comparison of the costs of living and materialized labor in transport for a correct comparison of labor productivity, for example, in JSC "Russian Railways".

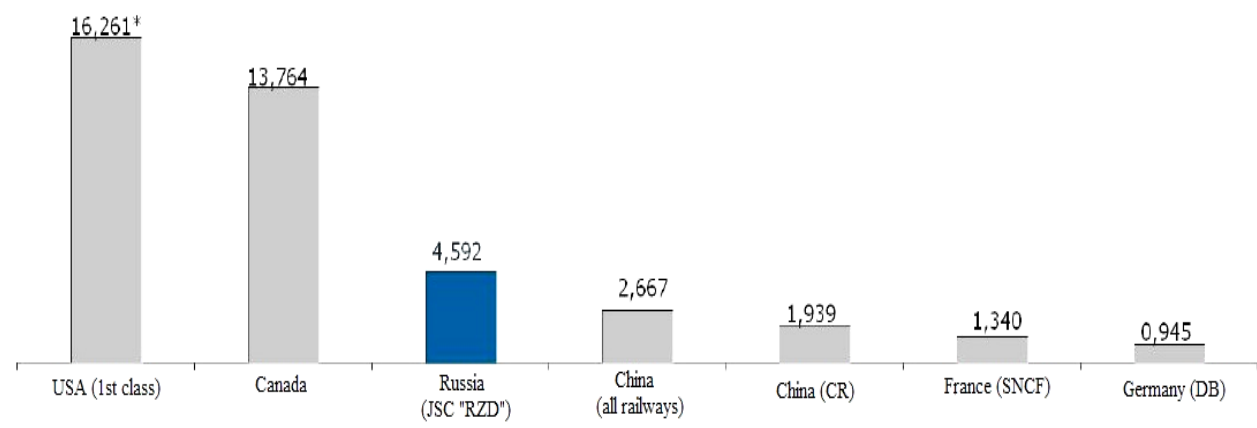

Fig. 2. The productivity of labor of railway workers in the world and JSC "Russian Railways" [1].

World experience shows that many managers of transport companies look at labor productivity remuneration systems as ineffectively reflecting the individual efficiency of labor, as purposeless compulsory payments - bonus payment, as pointing at contradictory performance guidelines for employees.

Therefore, when designing a labor productivity management system, a new methodological approach is to orient the management to form a model (Fig. 3) to manage the development of human potential and successfully adapt the personnel to the changing conditions of production activity, using new management methods [4].

The human potential realized in production processes, goods and services can provide the company with huge competitive advantages in the market. However, despite numerous slogans and appeals, the human potential and quality of the workforce has not become the subject of solving the problem of increasing labor productivity for most enterprises [5].

Therefore, it is necessary to create conditions in the company's structural subdivisions, in which the employees will be adequately assessed by the amount of material incentive for their contribution to the company's work. This will mean that if the company has succeeded in its work because the employees have worked hard and efficiently, realizing their potential, they deserve not a friendly pat on the back and a general "thank you" to everyone. If senior managers and shareholders receive higher returns from this effective work, should not all employees be involved in the process of introducing new methods of using human potential? $[4,6]$. 


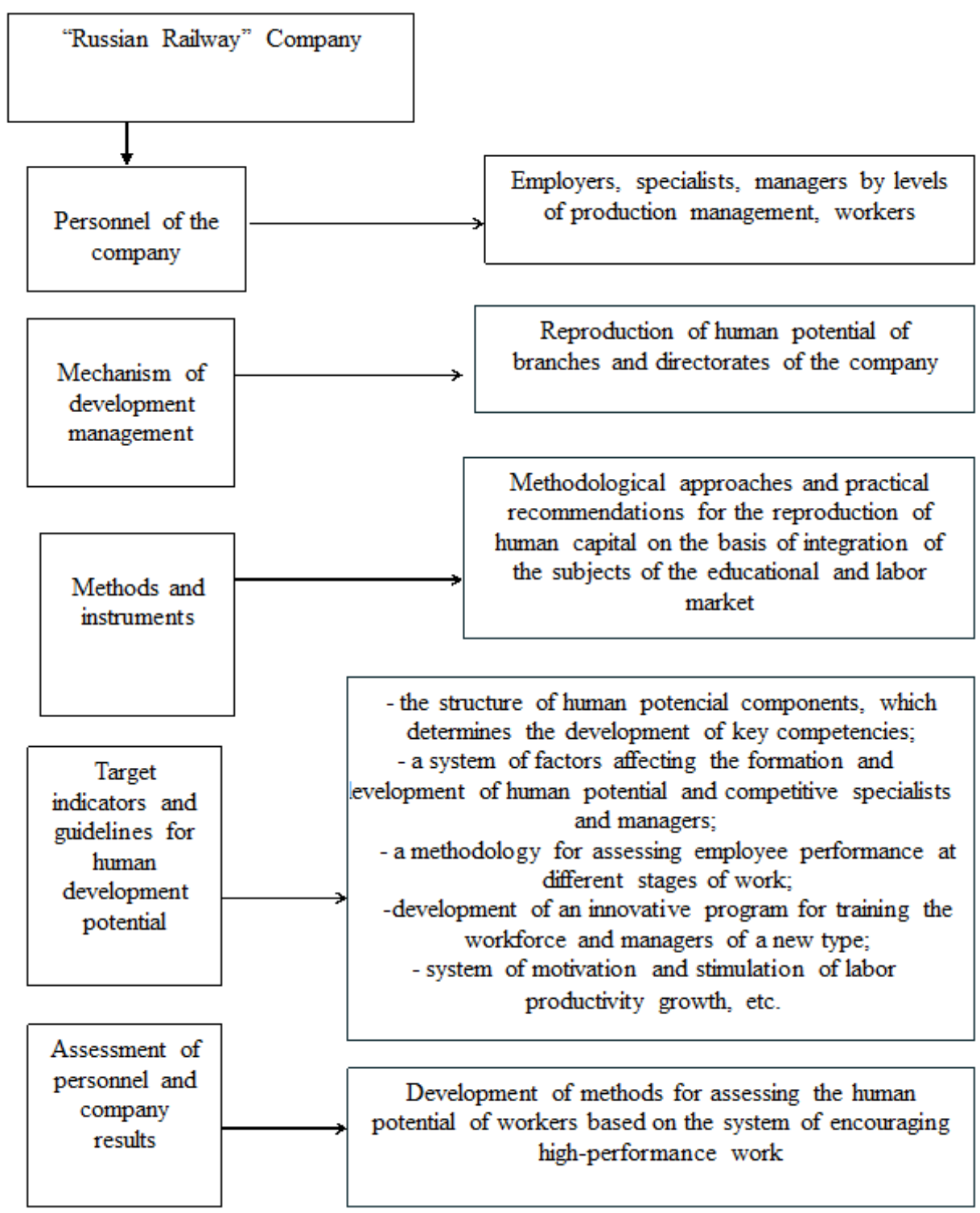

Fig. 3. Model of human potential reproduction management.

How can this be done? It is necessary to implement a process that ensures achievement of two important results:

1. How the incentive system is consistent with the indicators vital for the successful operation of the company.

2. Do the Board of Directors and the company's management create the conditions under which employees are highly interested in the results of their personal and collective work, are able to fully and completely realize their human capital?

When finding answers to these questions, a new model of employee incentives is formed in such a way that strengthens the company's competitiveness and improves the quality of customer service.

There is no universally correct way of encouraging employees, not every incentive system is equally effective. Therefore, it is necessary to establish factor and logical links, to 
form a model for managing the development of the company's human capital, affecting the efficiency of the production process through the implementation of encouraging and motivating remuneration functions (Fig. 3) [5]. The basic principles for the formation of this model should be the following:

- You cannot control what you cannot measure. Managers and specialists should determine the assessment and ensure recognition of performance indicators of personnel.

- You cannot improve what you cannot measure. It is impossible to test the system without data on work before and after its introduction to determine whether labor productivity and efficiency have actually increased.

- Highly efficient branches, subsidiaries and individual employees require clear goals. To achieve high labor productivity, it is necessary to determine in which direction to move.

- Payment for productivity and efficiency of labor requires assessment criteria. If you intend to pay for efficiency, you need to somehow know whether the employee has earned money paid.

- It is not always clear what results should be measured. In most cases, teams and individual workers whose performance is difficult to measure enjoy statistical indicators without asking questions, what results they should receive and how they find out that the work is done well enough.

- Even if you know what to measure, it is often not clear how to measure. Not all can be easily measured by figures and experts face the problem of measuring such indicators as "creativity", "initiative", "ability to efficient labor", etc.

The performance indicators of the company can also cause problems with labor productivity and efficiency if they are not known to the employee, are not balanced or are outside the sphere of employee influence. It often happens that the work team is at such deep levels in the organization of the production process that they do not know what indicators are important for the company as a whole and, naturally, they cannot affect what they do not know about (Figure 3).

Measuring as a process is quite laborious, even if you know how to perform it. Not all work can be measured by quantitative indicators. This process can be applied to qualitative, hard-to-measure work, as well as to easily measurable work in quantitative form [2, 4].

The method of measuring labor productivity of individual structural divisions and individual employees of a company requires, as a rule, a more complex methodology, which seems most suitable for the development of a suitable measurement technique.

In modern economic conditions, connection or alignments with the company's goals are increasingly important. Since there are different types of work in transport companies, different methods of measuring and assessing performance indicators are required. Therefore, the process of change for all companies is not linear. It is necessary to clearly understand the ultimate goal, which is to create a measurement system, which includes following elements:

- a list of priority indicators of company and personnel performance;

- indicators and key performance indicators of personnel and their normative values;

- the methodology for setting priorities and indicating the relative importance of collective and individual results;

Analyzing long-term experience of measuring the work performed in transport companies, the authors established a sequence of implementation of the model proposed by them (Fig. 3), which contributes to increasing the growth rates of labor productivity in the company, the transport industry and the real sector of the economy as a whole (Fig. 4). 


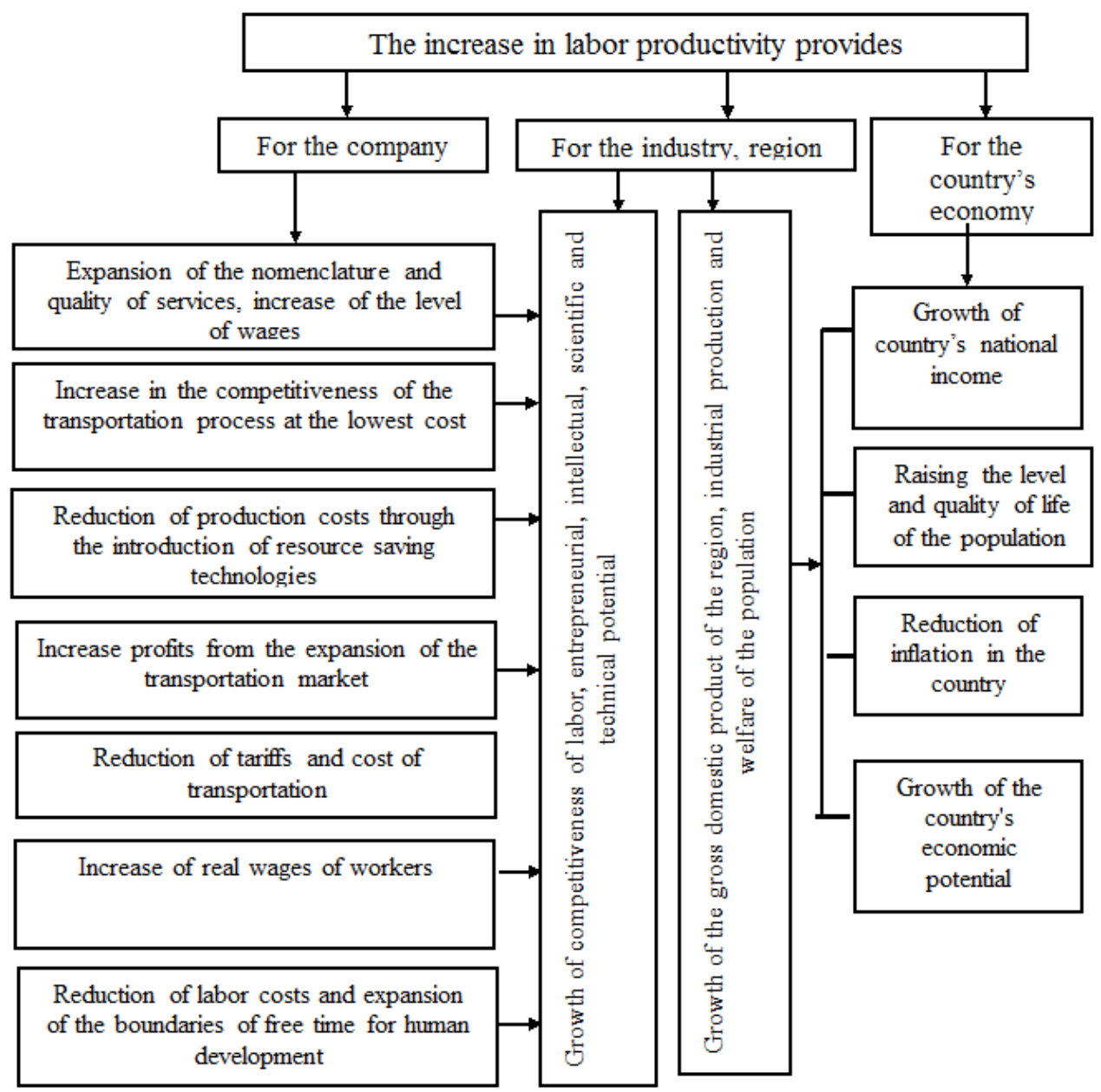

Fig. 4. Socio-economic functions of labor productivity.

1. Analyze the performance indicators of the company.

This stage allows us to punctually believe that the teams and employees know the indicators assigned to them, and how it's possible to establish a direct link between the influence of employees on the performance of the company's performance indicators $[4,7]$.

2. Determine the starting points for measurements.

Choose one of many (but not more than five) options for determining starting points for measurements. Choosing the best options and applying them to determine collective and individual results form the basis for all further measurements.

3. Determine the specific weight of each result.

Discuss and agree on the relative importance of each result with the help of which they will assess how effective the achieved results are.

4. Develop performance standards.

Define quantitative and qualitative indicators in their scope (plan and fact) "minimum and maximum" in order to meet or exceed projected expectations.

5. To suggest a method how to track performance: i.e. how to monitor, audit or diagnose production processes. At this stage of the process, take data on each standard of performance and in what form to represent them to teams and employees.

6. Analyze the performance of indicators directly or indirectly increasing the company's 
labor productivity, making a decision on indicators that are strategic goals, the achievement of which employees should contribute and which should be agreed with them.

All measurements affecting the effectiveness and productivity of labor should be conducted on the basis of collective or individual results, which increase the efficiency of production and the value of the output product [6].

This result is understood as such contribution of the company's team or individual employee to the overall result of the company, which is the result of their activity and increases the competitiveness of the products produced by the company. These results characterize the factor impact on overall performance and are the best starting point in three indicators:

- Time factor. Achieving an agreement on the result to be obtained takes less time than reaching agreement on the best order of actions required to achieve this result. And although there can be many ways to achieve the goal, everyone usually agrees more quickly about the "goal" than about the "means".

- Effectiveness factor. Assessment of the process of actions implies that there should be a person who will supervise the implementation of actions, although to assess the results of actions it is sufficient to check the result.

- The factor of realization of human capital. Personnel through their actions can make the labor process more productive, if the priority goal is not the activity to achieve the result.

After, it is necessary to develop a method for setting goals and determining the results that ensure achievement of performance indicators of the company (Fig. 5). Determination of the results ensuring achievement of performance indicators should give an answer to the question: what productive results created by a team or an employee can help a company achieve its goal $[5,7]$

The answer to this question helps specialists and managers to identify those results that are in their sphere of influence and which will ensure the success of all the company's activities.

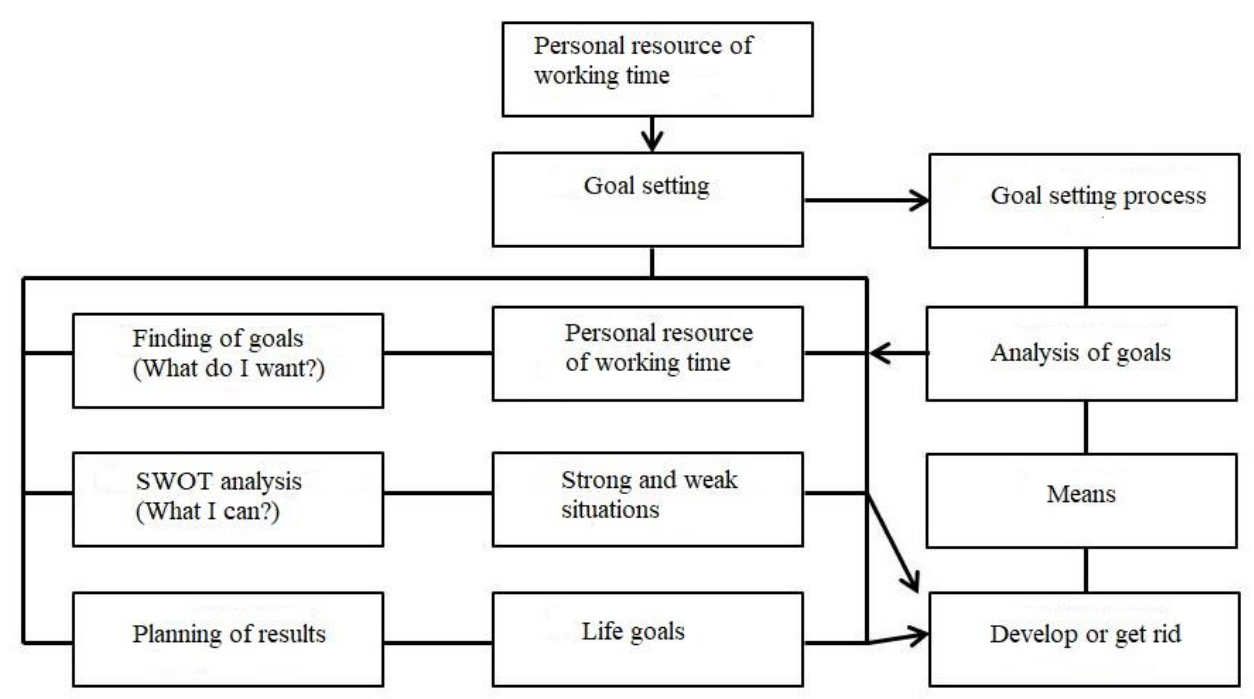

Fig. 5. The "goal-result" relationship of a specific employee.

In order to apply this method, the employee(s) responds(-) to two questions: "How can I (or we) influence the performance indicators of the company?" And if the answer is positive, then the next question: "What results that I (we) achieve can contribute to the 
achievement of the goal?" (Fig. 5) [2, 8].

Determining the starting points for measuring efficiency of work is to establish a hierarchy of results that the company must create and choose from them those that link the results of the employees' work with the results of the company. Linking the results of the team and the individual employee with the results of the organization ensures that the successful work of the performer will bring benefits to the organization. It is always necessary to link work of teams and employees with the results of the company's activities through indicators.

\section{References}

1. Works of the international scientific and practical conference "Improving labor productivity in transport - the source of development and competitiveness of the national economy" (2016)

2. F. Hertzberg, M. Miner, Sociological research, 3 (1990)

3. N.N. Gromov, V.A. Persianov, A.V. Kurbatov, A.G. Martynov, Management in transport (Publishing house "Academia", Moscow, 2003)

4. E.P. Golubkov, Marketing research: theory, methodology and practice (Publishing house "Finpress", Moscow, 1998)

5. A.V. Davydov, A.S. Ovsyanikov, N.M. Mallon, Motivation and labor remuneration in market economy (Science, Novosibirsk, 2003)

6. A.V. Davydov, S.P. Kretov, Managing human resources in the period of railway transport reform (Novosibirsk, 2002)

7. A.V. Davydov, A.P. Dementev, Railway transport, 2 (2002)

8. P.F. Drucker, Management Challenges for the 21st Century, textbook (Publishing house "Williams", Moscow, 2000) 